\title{
KULIT PISANG KEPOK (Muca Acuminate) MENURUNKAN KADAR MANGAN (Mn) PADA AIR SUMUR GALI
}

\author{
Raudhatul Jannah, Juanda, Hardiono \\ Poltekkes Kemenkes Banjarmasin Jurusan Kesehatan Lingkungan \\ Jl. H. Mistar Cokrokusumo No.1A Banjarbaru Kalimantan Selatan 70714 \\ E-mail: rjannahok33@gmail.com
}

\begin{abstract}
Banana Leather (Muca Acuminate) Decreases Manganese (Mn) In The Water Wells. This type of research is experimental in nature by conducting experiments with variations in the dose of banana skin kepok. The study design used was a pre test - post test control group. Data analysis uses one way Anova statistical test with $\alpha=0.05$. The population in this study was all dug well water in the working area of the Cempaka Banjarbaru Inpatient Health Center in 2020. The results of the analysis of Manganese $(\mathrm{Mn})$ decreased after treatment in each dose variation, the dose of banana peel $5 \mathrm{mg}$ can reduce levels of Manganese (Mn) by 6.1\% while the variation of the $25 \mathrm{mg}$ dose can reduce the levels of Manganese (Mn) by $83.1 \%$. Based on the Anova One Way statistical test results there was no significant decrease in the value of $p$ value (0.761)> $\alpha$ value (0.05). It is recommended for the community to improve the quality of well water. For related agencies, it is expected to supervise well water containing Mang.
\end{abstract}

Keyword: Kepok Banana Skin; Manganese Content (Mn); Dug Well Water

\begin{abstract}
Abstrak: Kulit Pisang Kepok (Muca Acuminate) Menurunkan Kadar Mangan (Mn) Pada Air Sumur Gali. Air merupakan sumber daya alam yang harus dilindungi agar tetap dapat dimanfaatkan oleh makhluk hidup. Masalah air saat ini adalah kandungan zat kimia yang tinggi contohnya Mangan (Mn). Salah satu cara menurunkan kadar Mangan (Mn) pada air sumur gali. Penelitian ini bertujuan Untuk mengetahui pengaruh kulit pisang kepok (muca acuminate) Terhadap kadar Mangan (Mn) pada air sumur gali. Jenis penelitian ini bersifat eksperimental yaitu melakukan percobaan dengan variasi dosis kulit pisang kepok. Desain penelitian menggunakan adalah pre test - post tes control group. Analisi data menggunkan uji statistik Anova one way dengan $\alpha=0,05$. Populasi dalam penelitian ini adalah seluruh air sumur gali di wilayah kerja Puskesmas Rawat Inap Cempaka Banjarbaru tahun 2020. Hasil analisis kadar Mangan (Mn) mengalami penurunan setelah dilakukan perlakuan disetiap variasi dosis, dosis kulit pisang kepok 5 mg mampu menurunkan kadar Mangan (Mn) sebesar 6,1\% sedangkan variasi dosis 25 mg dapat menurunkan kadar Mangan (Mn) sebesar 83,1\%. Berdasarkan hasil uji statistic Anova One Way tidak ada penurunan yang signifikan nilai Nilai $p(0,761)>$ nilai $\alpha(0,05)$. Disarankan untuk masyarakat guna memperbaiki kualitas air sumur. Bagi instansi terkait diharapkan untuk melakukan pengawasan terhadap air sumur yang mengandung kadar Mangan (Mn).
\end{abstract}

Kata Kunci: Kulit Pisang Kepok; Kadar Mangan (Mn); Air Sumur Gali

\section{PENDAHULUAN}

Air adalah sarana hidup dan kehidupan yang sangat penting dan menyangkut hajat hidup manusia, hewan maupun tumbuhan Seiring meningkatnya penduduk yang semakin pesat khususnya di daerah perkotaan yang padat penduduknya, sumber air bersih yang memenuhi syarat kesehatan semakin lama semakin sulit diperoleh.Hal ini menyebabkan air tanah menjadi alternative untuk memenuhi kebutuhan air bersih (Anisyah, dkk., 2013).

Menurut Kemenkes RI (2013), air yang dibutuhkan manusia, baik secara kualitas maupun kuantitas untuk memenuhi kebutuhan hidupnya, seperti untuk air minum, pengolahan makanan, 
pertanian, industri, perikanan, rekreasi dan olah raga maupun untuk pemenuhan lainnya, air yang tersedia seharusnya memenuhi persyaratan kesehatan (Rahayu, 2004). Menurut riset kesehatan dasar tahun 2013 menunjukkan bahwa jenis sumber air untuk seluruh kebutuhan rumah tangga di Indonesia pada umumnya adalah sumur gali terlindung yaitu $29,2 \%$, sumur pompa yaitu $24,1 \%$, dan air ledeng/PDAM yaitu19,7\% (Maharani, 2017).

Menurut Hendrawati (2013), Air tanah bisa mengandung zat besi (Fe) dan mangan $(\mathrm{Mn})$ yang cukup besar. Adanya kandungan $\mathrm{Fe}$ dan $\mathrm{Mn}$ dalam air menyebabkan warna air berubah menjadi kuning-coklat setelah beberapa saat kontak dengan udara. Selain mengganggu kesehatan juga dapat menimbulkan bau yang tidak sedap serta menyebabkan warna kuning pada dinding bak dan bercak-bercak kuning pada pakaian (Damayati,dkk., 2016).

Menurut Peraturan Menteri Kesehatan Republik Indonesia No. 492/Menkes/Per/IV/2010 tentang Persyaratan Kualitas Air Minum, Air besih dalam hal ini air tanah terkadang mengalami pencemaran-pencemaran air umumnya terjadi oleh tingkahlaku manusia seperti oleh zat-zat detergen, asam belerang dan zat-zat kimia sebagai sisa pembuangan pabrik-pabrik kimia/industri (Sunarsih dkk., 2018). Pada Peraturan tersebut syarat kekeruhan yaitu 0,5 NTU.

Mangan banyak ditemukan dilingkungan yaitu di udara airdan tanah merupakan unsur esensial bagi manusia dan hewan. Apabila mengekomsumsi yang kurang atau lebih dapat berdampak buruk pada kesehatan manusia terutama yang terpapar mangan dari makanan. Meskipun mangan merupakan salah satu unsur esensial bagi manusia dan hewan, tetapi paparan kronis sampai pada dosis yang tinggi dapat membahayakan kesehatan dengan target adalah sistem saraf. Suatu studi epidemiologi yang dilakukan di Yunani menunjukkan bahwa konsumsi air minum yang secara alami mengandung konsentrasi mangan yang cukup tinggi seumur hidup, berisiko menimbulkan gejala-gejala neurologi dan peningkatan retensi mangan. Hal tersebut ditandai oleh konsentrasi mangan yang tinggi dalam rambut penduduk berusia di atas 50 tahun (Ashar, 1888).

Menurut Thuraidah dkk (2015), kulit pisang kepok (Muca acuminate) merupakan bahan biomaterial yang dapat menyerap ion logam. Senyawa yang terkandung dalam kulit pisang kepok yaitu selulosa. Keberadaan selulosa ini yang menyebabkan kulit pisang kepok dapat menyerap ion logam. Ion logam yang bermuatan positif akan terikat oleh gugus hidroksil yang kaya dengan elektron. Limbah kulit pisang kepok dapat menurunkan kadar $\mathrm{Fe} 2+$ dalam larutan berair. Kulit pisang kepok juga dapat mengikat ion mangan dalam air sumur (Wardani \& Wulandari, 2018).

Pada penelitian juga akan mengunakan media kulit pisang kapok dengan parameter yang berbeda yaitu Mangan (Mn) pada sumur gali. Variasi yang digunakan adalah $5 \mathrm{mg}$ sampai 25 mg. Kulit pisang merupakan bahan buangan atau limbah buah pisang yang cukup banyak jumlahnya . Umumnya kulit pisang belum dimanfaatkan secara nyata, hanya dibuang sebagai limbah organik saja atau digunakan sebagai bahan makanan ternak seperti kambing, sapi dan karbau. Jumlah dari kulit pisang cukup banyak yaitu sekitar $1 / 3$ dari buah pisang yang belum dikupas. Kulit dari buah pisang kepok biasanya oleh masyarakat hanya dibuang dan hal itu menjadi permasalahan limbah di alam karena akan meningkatkan keasaman tanah dan mencemarkan lingkungan. Pengenalan penggunaan kulit pisang kepok kepada masyarakat akan lebih efektif bila diterapkan sebagai bahan baku dalam penurunan kadar Mangan (Mn) dalam sumur gali (Budiman dkk.,2018).

Menurut Susilawaty, $d k k$. (2015), kulit pisang kepok (Muca acuminate) merupakan salah satu bahan biomaterial yang dapat menyerap ion 
logam. Senyawa yang terkandung dalam kulit pisang kepok yaitu selulosa. Keberadaan selulosa yang menyebabkan kulit pisang kepok dapat menyerap ion logam. Ion logam yang bermuatan positif akan terikat oleh gugus hidroksil yang kaya dengan elektron. mengikat ion mangan dalam air sumur (Thuraidah dan Kartiko, 2015).

Zat mangan efektif menghilangkan dengan proses pelunakan dapat membuat pH menjadi 9,5 yang merupakan kondisi yang baik untuk oksidasi mangan dan besi. Berdasarkan hubungan $\mathrm{pH}$ dengan kelarutan 83\% mangan akan menge ndap maksimum pada pH 9,4 - 9,8 sebanyak 98 - 100\%. Lime softening akan lebih efesien jika didahului dengan proses aerasi (MoCabe, Warren L, Julian C. Smith, 1985)

Peneliti melakukan uji pendahuluan di Desa Pumpung Kecamatan Cempaka dari 4 sumur gali yang diperiksa parameter Mangan (Mn) dengan hasil $1.96 \mathrm{mg} / \mathrm{l}, 1.78 \mathrm{mg} / \mathrm{l}, 1.67 \mathrm{mg} / \mathrm{l}$ dan 1.82 mg/l berdasarkan Peraturan Menteri Kesehatan Republik Indonesia Nomor 492/Menkes/PER/IV/2010 dinyatakan melebihi standar baku mutu Mangan yaitu $0.4 \mathrm{mg} / \mathrm{l}$. Air sumur gali digunakan masyarakat tersebut untuk kegiatan sehari-hari. Jika kadar Mangan (Mn) tinggi, maka dapat membahayakan kesehatan. Kadar Mangan (Mn) berlebih dapat mengakibatkan banyak penyakit pada tubuh contohnya demam, sistem saraf, Selain itu dapat membuat pakaian kuning, serta membuat benda logam berkarat. Berdasarkan hal di atas, penelitian ini akan menggunakan limbah kulit pisang kepok (musca acuminate) untuk menurunkan kadar Mangan (Mn) pada sumur gali karena salah satu kandungan yang terdapat di dalam kulit pisang, yaitu galacturonic yang dapat mengikat berbagai logam berat. Faktor pendukung lainnya yaitu kadar Mangan (Mn) yang tinggi pada sumur gali di Desa Pumpung Cempaka Banjarbaru.

\section{BAHAN DAN CARA PENELITIAN}

Jenis penelitian ini adalah
eksperimen murni (true experiment.)
Desain penelitian yang digunakan adalah pre test - post tes control group Populasi dalam penelitian ini adalah seluruh air sumur gali di wilayah kerja Puskesmas Rawat Inap Cempaka Banjarbaru tahun 2020. Sampel dalam penelitian ini adalah salah satu sampel air sumur gali di wiliayah kerja puskesmas rawat inap Cemapaka Banjarbaru yang mengandung kadar Mangan (Mn) yang tinggi.

\section{HASIL PENELITIAN DAN PEMBAHASAN Pengaruh Suhu dan pH pada saat penelitian}

Pada saat pengambilan sampel air sumur sebelum perlakuan adalah suhu $31,8{ }^{\circ} \mathrm{C}$ dengan $\mathrm{pH}$ 6,2 dan sesudah perlakuan suhu $33,5^{\circ} \mathrm{C}$ dengan $\mathrm{pH}$ 5,9. Menurut Metzger (2005) dan Sawyer dkk. (1994), pH berbandingan terbalik dengan konsentrasi ion mangan $(\mathrm{Mn})$, di mana jika $\mathrm{pH}$ rendah maka kelarutan ion mangan (Mn) dalam bentuk $\mathrm{Mn}^{2+}$ dan $\mathrm{Mn}^{3+}$ di air tinggi. Sebaliknya, nilai $\mathrm{pH}$ yang tinggi membuat ion Mangan (Mn) dalam air menjadi bentuk endapan sehingga konsentrasinya dalam air rendah. Pemilihan kulit pisang yaitu pada pisang yang masih muda karena masih mengandung banyak Asam Galacturonic. Kandungan bersifat lekat dan dapat menyebabkan rasa lengket, pada saat pengupasan kulit pisang kepok. Maka dari itu, digunakan untuk mengikat kadar Mangan (Mn) yang tinggi pada air sumur.

Ditinjau dari sifat fisika Asam Galacturonic dapat bersifat koloid reversisbel, yaitu dapat dilarutakan dalam air, diendapkan, dikeringkan dan dilarutkan kembali tanpa perubahan fisiknya. Penggunaan kulit pisang kepok tanpa melakukan perlakukan khusus tidak mengubah dari sifat asam tersebut. Berdasarkan Penelitian Tamzil Aziz, 2018. Diketahui bahwa larutan asam akan meningkatnya derajat esterifikasi dan turunya berat molekul. Semakin mudah asam larut dalam air maka akan semakin mudah untuk mengendapkannya dengan suatu larutan elektrolit. Konsentrasi ion mangan karbondioksida terlarut (Dvorak dan Skipton, 2008). Kelarurtan ion Mangan akan meningkat apabila 02 
rendah CO2 tinggi. Sebaliknya, kelarutan mangan (Mn) akan menurun apabila kandungan $\mathrm{O} 2$ tinggi dan $\mathrm{CO} 2$ rendah. Konsentrasi oksigen yang tinggi dalam air akan dapat mengoksidasi kandungan Mangan (Mn), yang kemudian akan menjadi bentuk mengendap dalam air, sementara kandungan dioksida yang tinggi dalam air akan meningkatkan keasaman, karena CO2 dapat dengan mudah larut dalam air menjadi asam (H2CO3).

Menurut Hewwet dkk (2011), mengatakan bahwa kulit pisang kepok (Muca Acuminate) didalamnya mengandung beberapa komponen biokimia, antara lain selulosa, hemiselulosa, pigmen klorofil, dan zat pectin yang mengandung Asama Galacturonic. Asam inilah yang dapat mengikat ion logam. Waktu yang digunakan dalam penelitian ini adalah 60 menit.
Hal ini sejalan dengan hasil penelitian bahwa ada perubahan kadar Mangan (Mn), Suhu dan $\mathrm{pH}$ sesudah Perlakuan, setingga peneliti menyimpulkan ada pengaruh penambahan kulit pisang kepok pada air sumur gali namun perubahan kadar Mangan (Mn) secara statistik didapatkan ada pengaruh yang bermakna terhadap penurun kadar Mangan (Mn). Nilai $\mathrm{p}$ $(0,000)>$ nilai $\alpha(0,05)$.

\section{Dosis Optimal yang Digunakan Untuk Menurunkan Kadar Mangan (Mn) Pada Air Sumur Gali}

Untuk mengetahuai kadar Mangan (Mn) yang terkandung pada air sumur di wilayah Cempaka Banjarbaru dilakukan pemeriksaan sesuai dengan SNI 6989.4 2009. Sampel air diambil dengan menggunakan botol dan dilakukan pengulangan 4 Kali. Berdasarkan hasil penelitian dapat dilihat pada tabel 1 sebagai berikut:

Tabel 1 Hasil Pengukuran Kadar Mangan (Mn) Sebelum dan Sesudah Perlakuan

\begin{tabular}{|c|c|c|c|c|c|c|}
\hline \multirow{2}{*}{ Perlakuan } & \multicolumn{7}{|c|}{ Kadar Mangan } \\
\cline { 2 - 7 } & $\begin{array}{c}\text { Kontr } \\
\text { ol }\end{array}$ & $5 \mathrm{mg}$ & $10 \mathrm{mg}$ & $15 \mathrm{mg}$ & $20 \mathrm{mg}$ & $25 \mathrm{mg}$ \\
\hline 1 & 1,101 & 1,04 & 0,73 & 0,71 & 0,54 & 0,27 \\
\hline 2 & 1,121 & 1,19 & 1,08 & 0,93 & 0,50 & 0,33 \\
\hline 3 & 1,091 & 0,92 & 0,91 & 0,68 & 0,59 & 0,33 \\
\hline 4 & 1,132 & 1,03 & 0,77 & 0,54 & 0,39 & 0,30 \\
\hline Rata -rata & 1,111 & 1,045 & 0,872 & 0,715 & 0,505 & 0,307 \\
\hline
\end{tabular}

Berdasarkan table 1 Hasil Pengukuran Kadar Mangan (Mn) bahwa kadar Mangan Tertinggi berada pada perlakuan pertama dengan variasi dosis sebanyak 25 gr yaitu 0,27 dan terjadi penurunann sebesar $83,1 \%$. Sedangkan pengukuran kadar Mangan (Mn) terendah pada pengulangan pertama dengan variasi dosis sebanyak 5 gr dan terjadi penurunan kadar Mangan (Mn) sebesar $6,1 \%$. 


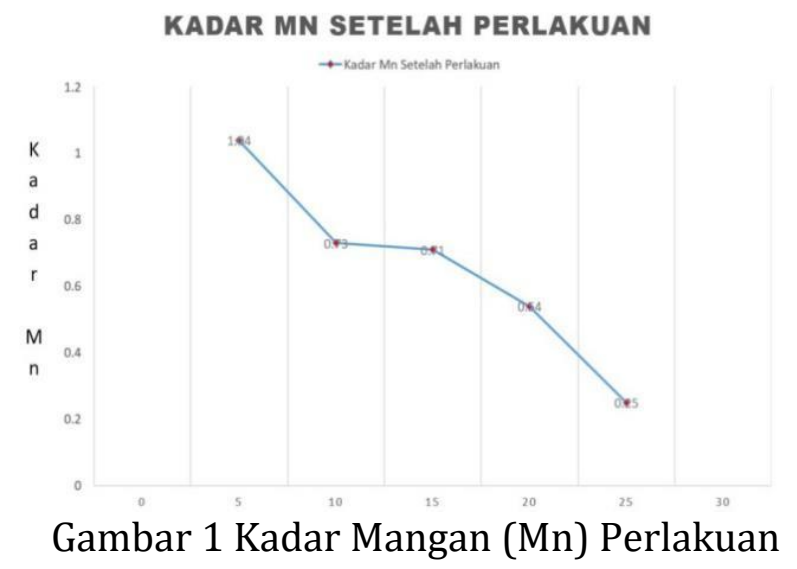

Berdasarkan hasil Gambar 5.1
Kadar Mangan $(\mathrm{Mn})$ mengalami
penurunan yang signifikan seiring dengan
dosis kulit pisang kepok yang dimasukkan
ke dalam sampel air. Kadar Mangan (Mn)

tertinggi berada pada $1,04 \mathrm{mg} / \mathrm{L}$ dengan variasi dosis $5 \mathrm{mg}$ sedangkan yang terendah pada $0,27 \mathrm{mg} / \mathrm{L}$ dengan variasi dosis $25 \mathrm{mg}$.

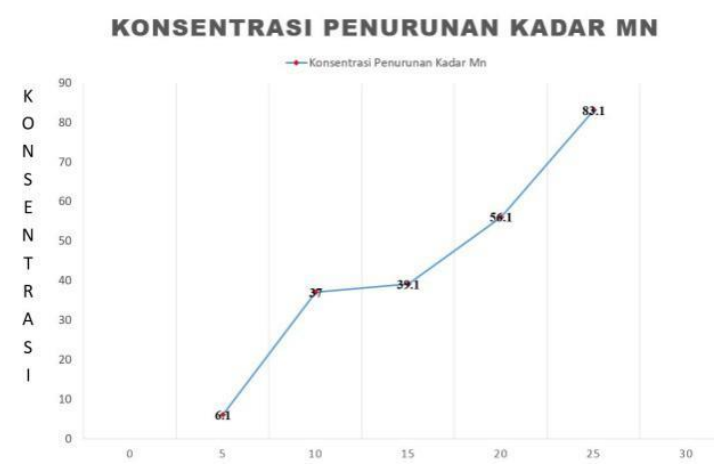

Gambar 5.2 Konsentrasi Penurunan Kadar Mangan (Mn)

Berdasarkan gambar 5.2 diketahui bahwa konsentrasi penurunan kadar Mangan (Mn) tertinggi sebesar 83,1\% pada dosis $25 \mathrm{mg}$ dan yang terrendah sebesar $6,1 \%$ dengan dosis $5 \mathrm{mg}$.

Dari hasil pemeriksaan didapatkan hasil untuk penambahan kulit pisang kepok dengan dosis 25 gr dengan metode jar test ternyata mampu menurunkan kadar Mangan (Mn) sebanyak 83,1,\%. Hal ini dapat dilihat pada grafik penurunan kadar Mangan (Mn) dari 1,101 mg/L menjadi 0,27 mg/L artinya hasil uji ini dapat menurunkan kadar Mangan (Mn) hingga memenuhi syarat pengawasan kualitas air bersih oleh permenkes RI No.32 Tahun 2017 atau bahkan dibawah baku mutu.

Menurut Moc.Cabe, dkk (1985) Kadar Mangan dapat mengendap pada $\mathrm{pH}$
9,4 sampai 9,8 Sebanyak 98 Sampai 100 $\%$ pada penelitian ini kadar Mangan dapat turun sebesar 83,1\% dengan pH 5,9.

\section{Pengaruh Pemberian Dosis Kulit Pisang Kepok Dalam Penurunan Kadar Mangan (Mn)}

Data hasil pemeriksaan kadar Mangan (Mn) pada air dilakukan perlakuan berupa penambahan kulit pisang kepok bertujuan untuk menurunkan kadar Mangan (Mn) pada air sumur gali. Hasil uji Anova One Way yang didapatkan tidak ada pengaruh yang bermakna terhadap penurun kadar Mangan (Mn). Nilai p $(0,000)>$ nilai $\alpha$ $(0,05)$.

Sebagai sumber air yang digunakan masyarakat di wilayah cemapak Banjarbaru adalah sumur gali. 
Sumur gali menyedikan air yang berasal dari lapisan tanah relative dekat dari permukaan tanah, oleh karena itu dengan mudah terkena kontaminasi melalui rembesan. Umumnya rembesan berasal dari tempat buangan kotoran manusia/jamban dan hewan, juga dari limbah sumur itu sendiri. Mangan (Mn) dapat menimbulkan penyakit juga dapat menganggu estetika, jika terlalu tinggi kandunganya zat Mangan (Mn) maka akan menimbulkan bau serta warna kekuningan pada pakaian.

Proses adsorpsi logam Mangan (Mn) dalam air dapat dilakukan dengan menggunakan kulit pisang kepok (Muca acuminate) memiliki kandungan vitamin C, vitamin B, kalsium, lemak, selulosa, rhamnosa, hemiselulosa, pigmen, klorofil, arabinose, galaktos dan asam galactoronic. Berdasarkan hasil penelitian

\section{KESIMPULAN DAN SARAN}

Berdasarkan hasil penelitian yang telah dilakukan dapat disimpulkan sebagai berikut :

1. Kadar Mangan (Mn) pada air sumur gali sebelum perlakuan pertama adalah 1,101, perlakuan kedua 1,121, perlakuan ketiga 1,091 dan perlakuan keempat 1,132 dengan suhu $31,8{ }^{\circ} \mathrm{C}$ dengan pH 6,2.

2. Kadar Mangan (Mn) pada air sumur gali sesudah dengan variasi dosis 5

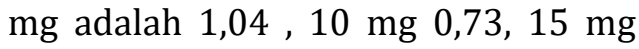
$0,71,20 \mathrm{mg} 0,54$ dan $25 \mathrm{mg} \mathrm{0,27}$ dengan suhu $33,5^{\circ} \mathrm{C}$ dengan $\mathrm{pH} 5,9$.

3. Ada pengaruh yang bermakna terhadap penurun kadar Mangan (Mn) dengan Nilai $\mathrm{p}(0,000)>$ nilai $\alpha$ $(0,05)$.

4. Bagi masyarkat sebagai guna untuk memperbaiki kualitas air sumur.

5. Bagi instansi terkait diharapkan untuk melakukan pengawasan terhadap air sumur yang mengandung kadar Mangan (Mn).

\section{KEPUSTAKAAN}

1. Arizka Yulianti. (2015). Prototype Alat Pengolahan Air Laut Menjadi Air Minum (Pengaruh Variasi Packing Filter Terhadap Kualitas yang dilakukan oleh Hossain dan Nguyen (2012), asam galactoronic merupakan gula karboksil yang dapat mengikat ion logam Mangan (Mn)

Pengambilan sampel air sumur di wilayah Cempaka Banjarbaru ini di ambil secara purposive sampling atau berdasarkan pertimbangan dari peneliti, yaitu sumur gali yang digunakan adalah sumur gali terbuka.

Dalam penelitian ini menggunakan variasi dosis kulit pisang untuk mengetahui dosis optimal yang dapat menurunkan kadar Mangan (Mn) pada air sumur gali. Variasi dosis yang digunakan sebagai berikut: 1) $5 \mathrm{mg}$, 2) $10 \mathrm{mg}$, 3) 15 mg, 4) $20 \mathrm{mg}$, dan 5) $25 \mathrm{mg}$.kulit pisang kepok langsung dimasukan kedalam sampel air sumur tanpa perlakuan khusus terlebih dahulu dengan beberapa variasi dosis setelah itu aduk dalam floctulator.

Air Dengan Analisa Do, Salinitas, Dan Konduktivitas) (Vol. 151). https://doi.org/10.1145/313284 7.3132886

2. Anny Thuraidah, Jasmadi Joko Kartiko, L. F. A. (2015). Kulit Pisang Kepok (Musa Paradisiaca L.) Untuk Menurunkan Kadar Mangan Air Sumur Anny. Medical Laboratory Technology Journal, 1(1), 19-26.

3. Andini NAM, 2014. Pengaruh pemberian eskstrak etanol kulit pisang ambon dan kulit pisang kepok terhadap kadar kolesterol total tikus putih jantan galur sprague dawley. Skrpsi. Lampung: Fakultas Kedokteran Universitas Lampung.

4. Bimawan, nanda arie. (2019). efektivitas kulit pisang kepok terhadap penurunan kadar besi (fe) dengan metode jar test pada air sumur gali. Politeknik Kesehatan Banjarmasin Program Studi Diploma IV Kesehatan Lingkungan.

5. Budiman, Hamidah, \& Hasria. (2018). Limbah Kulit Pisang Kepok ( Musa Acuminate) Sebagai Biofilter Zat Besi ( $\mathrm{Fe}$ ) Dan Zat Kapur ( $\mathrm{CaCO3}$ ) Skin Waste of 
Kepok Banana (Musa Acuminate) As A Biofilter Of Iron ( $\mathrm{Fe}$ ) And Calcium ( $\mathrm{CaCO} 3$ ). 8(November), 152-158.

6. C.D. Soemarto, 1987 : Hidrologi Teknik, Usaha Nasional, Surabaya.

7. Dr. Ir. Budiyono, M.Si. dan Dr. Siswo Sumardiono, S.T., M. T. (2013). teknologi pengolahan air. Penerbit: Graha Ilmu

8. Dharmayanti, A., dan Martak F. (2015) Sintesis Senyawa Aktif Kompleks Mangan(II) dengan Ligan 2(4-nitrofenil)-4,5-difenil1H-imidazol. Jurnal Sains Dan Seni ITS Vol. 4, No.2, (2015)

9. Elysia, V. (2015). Air Dan Sanitasi : Dimana Posisi Indonesia? A I R $D$ a N S a I T a I : DIM a N a POS I S I I N D O N E S I a ?, 157-179.

10. hossain, MA.,HH.Ngo, W.S.Guo., T. V. N. (2012). biosorption of cu(II) from water by banan peel based biosorbent. Journal of Energy \& Environment 3 (2): 143-156, 2012.

11. MoCabe, Warren L , Julian C. Smith, P. H. (1985). Operasi teknik kimia,Erlangga Jakarta.

12. Manurung, T., Dewi, Y. S., \& Lekatompessy, B. J. (2012). Volume 8 No.1 Maret 2012. Jurnal Ilmiah Fakultas Teknik (LIMIT'S), 8(1), 37-46.

13. Nino, S., \& Saptoadi, W. (2001). Pengaruh konsentrasi kalsium ( $\mathrm{Ca}$ ) dan mangan ( $M n$ ). ( Kasus pada delapan penampang di saluran induk Tarum Barat J.Program Studi Teknik Sipil

14. Notoatmodjo, S. (2012). Metodologi Penelitian Kesehatan. Jakarta Rineka Cipta

15. Nine Elissa Maharani, W. (2017). 1 , 2 1,2. Efektivitas Filter Serpihan Marmer Terhadap Penurunan Kadar Besi, Mangan Dan Magnesium Pada Air Sumur Gali Nine, 10(1), 1-8.

16. Nazir. Moh. 1983. Metode Penelitian. Jakarta : Ghalia Indonesia

17. Ricki M. Mulia. (2005). kesehatan lingkungan. Yogyakarta: Graha Ilmu

18. Rustanti, M. E. (2018). Potensi Kulit Pisang Kepok Kuning (Muca Paradisiaca P) Sebagai Bahan Tambahan Dalam Pembuatan Es Krim. Skripsi thesis, Sanata Dharma University

19. Said, N. I. (2005). Metoda penghilangan zat besi dan mangan di dalam penyediaan air minum domestik. 1(3). Jurnal Air Indonesia

20. Sari, F. G. T. (2016). Kajian Kandungan Logam Berat Mangan (Mn) Dan Nikel (Ni) Pada Sedimen Di Sekitar Pesisir Teluk Lampung. Nalytical And Environmental Chemistry, E-ISSN25408267Volume 1, No 01, Oktober2016

21. Suryanto, H. (2016). Review Serat Alam: Komposisi, Struktur dan Sifat Mekanis. ResearchGate, (October), 1-14. Jurusan Teknik Mesin, Fakultas Teknik, Universitas Negeri Malang

22. Syafi'udin imam. (2019). Pengaruh Kadar Mangan (Mn) Terhadap Struktur Mikro dan Kekerasan Baja Paduan Fe-17CrxMn Melalui Metode Peleburan (Vol. 53). https://doi.org/10.1017/CB0978 1107415324.004.

23. Sunarsih, E., Faisya, A. F., Windusari, Y., Trisnaini, I., Arista, D., Septiawati, D., ... Garmini, R. (2018). Analisis Paparan Kadmium , Besi, Dan Mangan Pada Air Terhadap Gangguan Kulit Pada Masyarakat Desa Ibul Besar Kecamatan Indralaya Selatan Kabupaten Ogan Ilir. 17(32), 6873

24. Tuhuloula, A., Budiyarti, L., \& Fitriana, E. N. (2013). Karakterisasi Pektin Dengan Memanfaatkan Limbah Kulit Pisang Menggunakan Metode Ekstraksi. Jurnal Konversi, 2(1), 21-27. 
25. Wahyudi, S. (2013). uji kualitas fisik air pada sarana air bersih program penyediaan air minum dan berbasis masyarakat (PAMSIMAS) di Desa Ilohungayo kecamatan batudaa kabupaten gorontalo. Program Studi Kesehatan Masyarakat
26. Widia Wati. (2016). Kajian Kualitas Air Sumur Gali Sebagai Sumber Air Minumdi Pekon Sukamarga Kecamatan Suoh Kabupaten Lampung Barat Tahun 2016. Fakultas Keguruan Dan Ilmu Pendidikan. 